\title{
Application of the Healthy Eating Index-2010 to the hunger relief system
}

\author{
Marilyn S Nanney ${ }^{1, *}$, Katherine Y Grannon ${ }^{1}$, Colin Cureton ${ }^{2}$, Courtney Hoolihan ${ }^{1}$, \\ Mark Janowiec ${ }^{1}$, Qi Wang ${ }^{3}$, Cael Warren ${ }^{2}$ and Robert P King ${ }^{2}$ \\ 'Department of Family Medicine \& Community Health, Program in Health Disparities Research, University of \\ Minnesota, 717 Delaware Street SE, Minneapolis, MN 55414, USA: ${ }^{2}$ Department of Applied Economics, University \\ of Minnesota, St Paul, MN, USA: ${ }^{3}$ Clinical and Translational Science Institute, Biostatistical Design and Analysis \\ Center, University of Minnesota, Minneapolis, MN, USA
}

Submitted 2 July 2015: Final revision received 11 April 2016: Accepted 19 April 2016: First published online 25 May 2016

\begin{abstract}
Objective: To demonstrate the feasibility of applying the Healthy Eating Index2010 (HEI-2010) to the hunger relief setting, specifically by assessing the nutritional quality of foods ordered by food shelves (front-line food provider) from food banks (warehouse of foods).

Design: This Healthy FOOD (Feedback On Ordering Decisions) observational study used electronic invoices detailing orders made by 269 food shelves in 2013 and analysed in 2015 from two large Minnesota, USA food banks to generate HEI-2010 scores. Initial development and processing procedures are described. Results: The average total HEI-2010 score for the 269 food shelves was 62.7 out of 100 with a range from 28 to 82 . Mean component scores for total protein foods, total vegetables, fatty acids, and seafood and plant proteins were the highest. Mean component score for whole grains was the lowest followed by dairy, total fruits, refined grains and sodium. Food shelves located in micropolitan areas and the largest food shelves had the highest HEI-2010 scores. Town/rural and smaller food shelves had the lowest scores. Monthly and seasonal differences in scores were detected. Limitations to this approach are identified.

Conclusions: Calculating HEI-2010 for food shelves using electronic invoice data is novel and feasible, albeit with limitations. HEI-2010 scores for 2013 identify room for improvement in nearly all food shelves, especially the smallest agencies. The utility of providing HEI-2010 scores to decision makers in the hunger relief setting is an issue requiring urgent study.
\end{abstract}

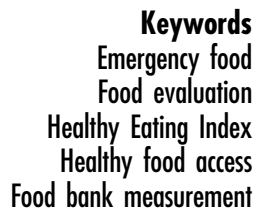

Emergency food Food evaluation ealthy Eating Index ood bank measurement
Hunger relief organizations in the USA such as food shelves, sometimes called food pantries, are an important resource for low-income households. In 2014, Feeding America, the nation's largest domestic hunger relief organization, provided food assistance to 46 million people in the USA, including 12 million children and 7 million seniors, through its network of 200 food banks and 58000 feeding programmes ${ }^{(1)}$. Food banks usually operate on the 'warehouse' model, serving as food storage and distribution depots for front-line agencies and typically do not give out food directly. Food shelves, however, do operate on the 'front line', serving families and individuals in need directly at no or very low cost ${ }^{(2)}$. Much of the food distributed by food shelves is donated from grocery stores or large food companies, collected as 'lost harvest' from local or regional farms, donated through food drives or obtained from food banks, either free or purchased. Families who depend on the food shelf distribution model either 'shop' for their food or are given a pre-assembled bag of food, all free of charge or at low cost.

Food shelf clients generally have low incomes and are therefore more likely to experience food insecurity and other diet-related health challenges ${ }^{(3)}$. Food insecurity rates are highest in households with children headed by single women or men, in black and Hispanic households, and in households with incomes below $185 \%$ of the poverty threshold ${ }^{(4)}$.

Rates of obesity and type 2 diabetes in the USA follow a socio-economic gradient, such that the burden of disease falls disproportionately on racial/ethnic minorities and people with limited resources ${ }^{(5)}$. A 2014 report by Feeding America identifies high prevalence rates of diet-related diseases among client households ${ }^{(3)}$. In more than half 
(58\%) of client households, at least one member reported having high blood pressure. In 33\% of client households, at least one member had diabetes. The rates of high blood pressure (77\%) and diabetes (47\%) were markedly higher among households with seniors. Food insecurity has been linked to lower diet quality ${ }^{(6)}$. Seasonal fluctuations influence access to quality produce and can also be a factor in diet quality among food shelf clients ${ }^{(7-9)}$.

Despite the need for hunger relief programmes and the food-related health risks faced by those they serve, there is no systematic monitoring or regulation of the nutritional quality of the food provided to families in need. In the USA there are thirteen federal nutrition assistance programmes that provide additional food sources to low-income and food-insecure families ${ }^{(10)}$. Programmes such as the Special Supplemental Nutrition Program for Women, Infants, and Children $^{(11)}$, the Child and Adult Care Food Program ${ }^{(12)}$, and the School Breakfast Program and National School Lunch Program $^{(13)}$ touch the lives of one in four Americans each year and, taken together, comprise America's nutrition safety net. The majority of these nutrition assistance programmes must meet nutrition standards, which are updated, regulated and monitored by the US Department of Agriculture (USDA). Oversight of the nutritional quality of these food safety net programmes is especially important due to the health disparities experienced by participants.

The Healthy Eating Index (HEI) was created by the USDA in 1995 to monitor the diet quality of the US population, assess the quality of nutrition programmes and examine the relationship between diet quality, cost and health outcomes ${ }^{(14)}$. There is strong evidence that the HEI is a valid and reliable measure of diet quality ${ }^{(14)}$. The HEI-2010 provides an overall score on a 0-100 point scale and twelve component scores that embody the major food patterns ${ }^{(14)}$. The components and their allowable ranges are: Total Fruits (0-5), Whole Fruits (0-5), Total Vegetables (0-5), Greens and Beans (0-5), Whole Grains (0-10), Dairy (0-10), Total Protein Foods (0-5), Seafood and Plant Proteins (0-5), Fatty Acids (0-10), Refined Grains (0-10), Sodium (0-10) and Empty Calories (0-20). The HEI is a standardized way to quantify adherence to the Dietary Guidelines for Americans for both individuals and broader food environments ${ }^{(14,15)}$. The closer an HEI score is to 100 , the more balanced and healthful the diet or food environment is. Among individuals, the HEI has been shown to be inversely related with risk of major chronic disease, overweight and obesity, and all-cause mortality ${ }^{(16,17)}$. In one study, women and men who most closely matched the goals of the 2005 Dietary Guidelines for Americans as assessed by the HEI-2005 were shown to have a 16\% lower risk of chronic disease, a $23 \%$ lower risk of $\mathrm{CHD}$ and an $18 \%$ lower risk for diabetes ${ }^{(18)}$. Applications of the HEI to broader food environments and settings include measures of the healthfulness of the US food supply, fast-food dollar menus and child-care menus ${ }^{(15,19-21)}$.
The purposes of the present paper are to describe the application of the HEI-2010 to the local hunger relief agency and to assess the nutritional quality of food ordered by food shelves from two food banks. This includes purchased food and food made available at no cost and an examination of seasonal variations. In addition, development of the measurement process is described and areas to improve upon identified. The potential for future applications within the hunger relief setting is discussed.

\section{Methods}

Data were collected as part of the Healthy FOOD (Feedback On Ordering Decisions) study at the University of Minnesota. The primary focus of the Healthy FOOD study was a 15-month randomized controlled trial in which invoices were collected from a subset of the food shelves ordering from one or both of two large Minnesota food banks: The Food Group (http://thefoodgroupmn.org/) and Second Harvest Heartland (http://www.2harvest.org/). Intervention food shelves received monthly feedback reports on their overall HEI-2010 score and all twelve component scores based on their invoices. The current study delivers a year-long observation of the food orders placed by all food shelves that ordered from The Food Group and/or Second Harvest Heartland during 2013. Food shelves were included in the sample if both food ordering and food distribution data were provided to either food bank. Electronic invoices provided the orders placed in 2013. For 2013, sixty-eight food shelves did not order from either food bank and four food shelves did not provide distribution data. The final study sample includes 269 Minnesota and Wisconsin food shelves.

Figure 1 describes the initial development process of preparing to receive the electronic invoices by developing a Master Food List database, importing publicly available databases, creating stored procedures to match invoice descriptions to the Master Food List database and preparing the HEI-2010 calculations, including necessary conversions.

\section{Initial development}

First, a total list of food products available to food shelves for order, either free of charge or for purchase in 2013, was obtained from the food banks. Second, to create a Master Food List database, a registered dietitian matched the food-bank-provided foods and each food's unique inventory number to product descriptions in the USDA's Food and Nutrient Database for Dietary Studies version 5.0 (FNDDS 5.0 $)^{(22)}$. To assess validity, a second registered dietitian independently performed the matching with a $10 \%$ sample of food products available in 2013 ( $n$ 211). Inter-rater reliability was assessed by calculating the percentage of agreement between the two coders (80\%). 


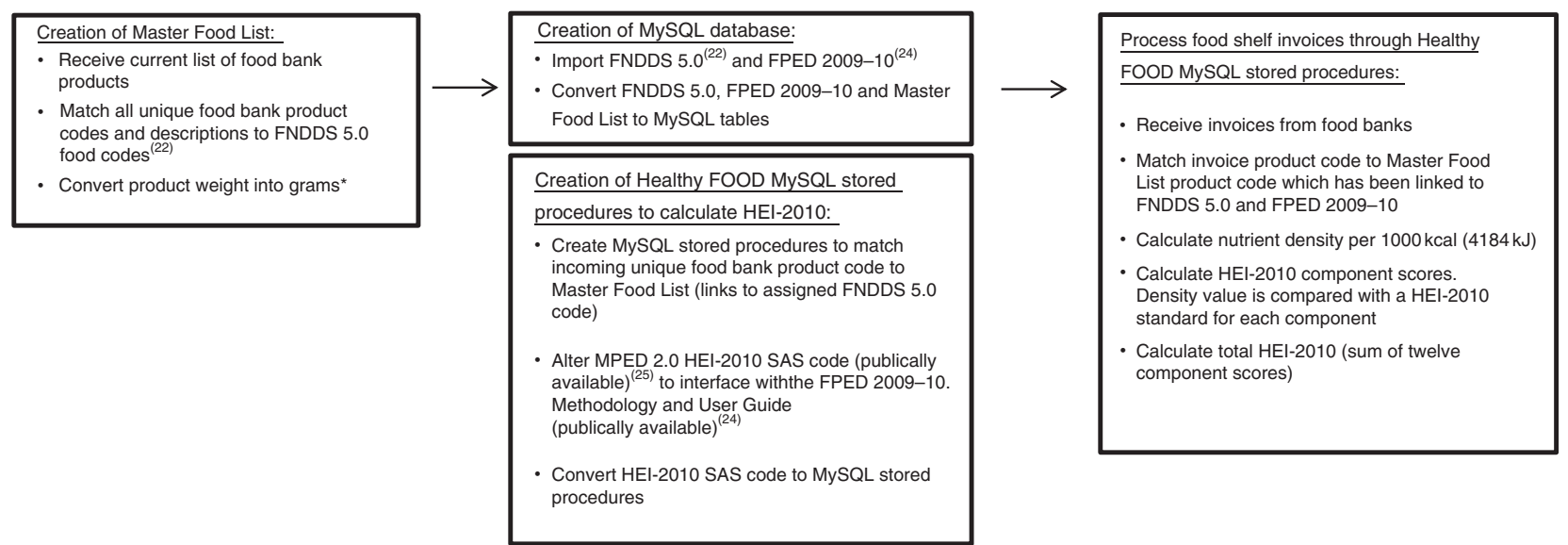

Fig. 1 Description of the Healthy FOOD (Feedback On Ordering Decisions) Heathy Eating Index-2010 (HEl-2010) scoring process. *Products listed in liquid ounces were converted to grams using the US Department of Agriculture's National Nutrient Database for Standard Reference ${ }^{(23)}$ (FNDDS 5.0, Food and Nutrient Database for Dietary Studies version 5.0; FPED 2009-10, Food Patterns Equivalent Database 2009-10; MPED 2.0, MyPyramid Equivalents Food Database version 2.0)

HEI-2010 scores based on the two separate coding assessments were 50.5 and 57. All disagreements were reconciled. Third, using invoice descriptions, net weights for items purchased were calculated using weight per item. The USDA Nutrient Database for Standard Reference (2014) was used to convert the volume of any non-dry, non-pre-packaged item from the invoices into its weight in grams ${ }^{(23)}$. This was also stored in the Master Food List.

Next, MySQL procedures were created to link incoming invoices to the Master Food List database, which ultimately linked the unique food bank inventory number to FNDDS 5.0 and the Food Patterns Equivalent Database 2009-10 (FPED 2009-10) ${ }^{(24)}$. The FPED 2009-10 disaggregates foods and beverages in the FNDDS 5.0 to food pattern components. The FPED 2009-10 and FNDDS 5.0 convert food items to nutrients and food patterns and capture total calories, monounsaturated and polyunsaturated fatty acids, and sodium, respectively.

Publicly available SAS macros provided by the National Cancer Institute ${ }^{(25)}$ were used to create the portion of the MySQL stored procedures which computed the HEI-2010 component and total scores based on energy density ratios. As the SAS macros provided by the National Cancer Institute were developed for use with the MyPyramid Equivalents Food Database version 2.0 (MPED 2.0), a USDA-provided conversion chart was used to convert those SAS macros to the FPED 2009-10 components. MPED 2.0 is a previous edition to FPED 2009-10. Publically available SAS macros allow for easy calculation of the HEI-2010 ${ }^{(25)}$. However, additional MySQL customization was done to further streamline the monthly and quarterly reporting for the Healthy FOOD study.

Figure 1 also describes important updating procedures. First, based on regular notification from the food banks, new foods available to food shelves and their unique food bank inventory number were added to the Master Food
List database. New foods also included size variations (e.g. \#10 can of corn, 14 ounce $(397 \mathrm{~g}$ ) cans of corn have unique food bank inventory identification numbers). Combined, our study food banks averaged twenty to twenty-five new foods per week. Second, batches of invoices were received monthly from each food bank. The Healthy FOOD study team programmer developed a customized JavaFX application for the purpose of importing invoice information. Invoices were imported into MySQL so their unique food bank inventory number could be matched to the Master Food List, which now included all the new products for that month. After development of all of the MySQL stored procedures, all 2013 invoices were processed. Following the steps described in Fig. 1, monthly total and component HEI-2010 scores were created for individual food shelves.

\section{Sample and description}

Data for the Healthy FOOD study were sourced from The Food Group and Second Harvest Heartland. In the event that data were inconsistent (e.g. address, reported pounds distributed), the information supplied by Second Harvest Heartland, the larger of the two food banks, was used. Table 1 describes the population of 269 food shelves evaluated by the current study. Definitions and calculations are as follows.

Geographic locations were assigned based upon the USDA Economic Research Service's Rural-Urban Commuting Area classification scheme ${ }^{(26)}$. This classification scheme uses census tract (2000) population density, urbanization and daily commuting data. For the current analysis, food shelves were assigned to metropolitan, micropolitan, small town and rural. The categories of micropolitan, small town and rural represent increasing distances from a metropolitan centre (e.g. near metro to far from metro, respectively). 
Table 1 Local, size and food ordering characteristics of 269 Minnesota and Wisconsin (USA) food shelves, 2013

\begin{tabular}{|c|c|c|c|}
\hline & $\%$ & Mean & Range \\
\hline \multicolumn{4}{|l|}{ Location* } \\
\hline Metropolitan ( $n$ 186) & $69 \cdot 1$ & & \\
\hline Micropolitan ( $n$ 13) & 4.8 & & \\
\hline Small town $(n 23)$ & $8 \cdot 6$ & & \\
\hline Rural ( $n$ 47) & 17.5 & & \\
\hline \multicolumn{4}{|l|}{ Age distribution of population served } \\
\hline Seniors & 9.8 & & \\
\hline Youth & $37 \cdot 7$ & & \\
\hline \multicolumn{4}{|l|}{ Food shelf size† } \\
\hline \multicolumn{2}{|l|}{ Total pounds distributed $(\mathrm{Ib})$} & \multicolumn{2}{|c|}{60085190} \\
\hline \multicolumn{2}{|l|}{ Average annual pounds distributed (Ib) } & 223365 & $475-2302500$ \\
\hline \multicolumn{2}{|l|}{ Smallest $(n 67)$} & 15062 & $475-35450$ \\
\hline \multicolumn{2}{|l|}{ Small-medium ( $n$ 67) } & 65348 & $35680-99165$ \\
\hline \multicolumn{2}{|l|}{ Medium-large $(n 68)$} & 175737 & $102245-269413$ \\
\hline \multirow{2}{*}{\multicolumn{2}{|c|}{$\begin{array}{l}\text { Largest ( } n \text { 67) } \\
\text { Food shelf ordering from food bankst }\end{array}$}} & 638025 & $272247-2302500$ \\
\hline & & \multicolumn{2}{|c|}{29071496} \\
\hline \multicolumn{2}{|l|}{ Total pounds ordered (lb) } & & 496 \\
\hline \multirow{2}{*}{\multicolumn{2}{|c|}{$\begin{array}{l}\text { Average annual pounds ordered (lb) } \\
\text { Total miscellaneous pounds ordered (lb)§ }\end{array}$}} & 108073 & $58-1533038$ \\
\hline & & \multirow{2}{*}{\multicolumn{2}{|c|}{10823205}} \\
\hline \multicolumn{2}{|l|}{ Average annual miscellaneous pounds ordered $(\mathrm{lb}) \S$} & & \\
\hline \multicolumn{4}{|l|}{ Average composition of miscellaneous food orders§ } \\
\hline Dry food & 34.6 & & \\
\hline Meat & 33.6 & & \\
\hline Produce & $11 \cdot 3$ & & \\
\hline Bakery & $10 \cdot 3$ & & \\
\hline Dairy & $5 \cdot 7$ & & \\
\hline Deli & $2 \cdot 5$ & & \\
\hline Frozen & 1.4 & & \\
\hline Beverages & 0.4 & & \\
\hline Seafood & 0.02 & & \\
\hline \multicolumn{4}{|l|}{ Food included in HEl-2010 scorell } \\
\hline \multicolumn{2}{|l|}{ Total pounds included in HEI-2010 (Ib) } & \multicolumn{2}{|c|}{18248292} \\
\hline Average annual pounds included in HEI-2010 (Ib) & & 67838 & $43-732031$ \\
\hline \multicolumn{4}{|c|}{ 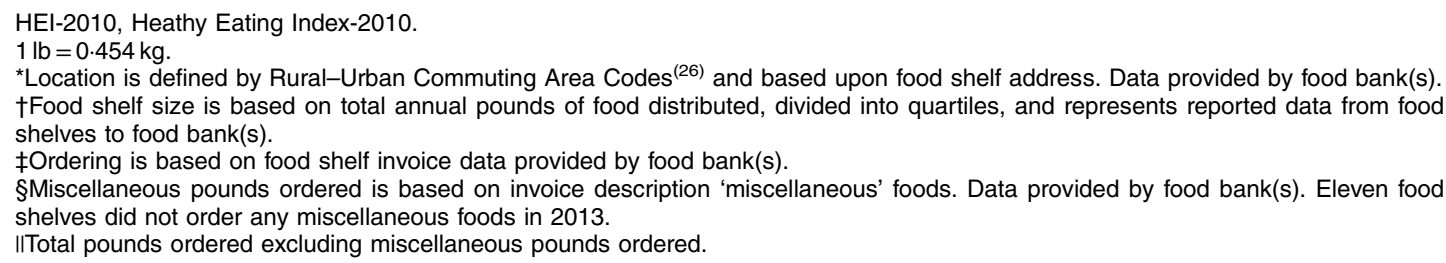 } \\
\hline
\end{tabular}

Geographically, nearly $70 \%$ of food shelves are located in metropolitan areas of Minnesota and Wisconsin.

Food shelf size is based on total pounds (lb) of food distributed and represents reported data from food shelves to food banks. Size categories were determined by dividing food shelves into quartiles by total pounds of food distributed. In 2013, the 269 food shelves reported distributing over 60 million $\mathrm{lb}(27.2$ million $\mathrm{kg})$ of food, ranging from $475 \mathrm{lb}(215.7 \mathrm{~kg})$ to over 2 million $\mathrm{lb}$ $(0.91$ million $\mathrm{kg}$ ) of food per food shelf. At a typical food shelf, $8 \%$ of individuals served were seniors and 39\% were youth. Not all foods represented on invoices were clearly defined. Nine 'miscellaneous' food categories were reported on invoices, which could not be included in the HEI-2010 calculations. Miscellaneous foods represented $27 \%$ of the food ordered on the invoices (the ratio of total miscellaneous pounds ordered to total pounds ordered). Two categories, dry food and meat, represented two-thirds of the miscellaneous pounds ordered. Only eleven food shelves did not order any miscellaneous foods in 2013.
Because food shelves obtain food from several sources, many food shelves distribute a great deal more food than they order from food banks. In fact, food ordered from food banks comprised only $48 \%$ of total food distributed by these food shelves in 2013 (the ratio of total pounds ordered to total pounds distributed). Both the existence of miscellaneous categories and the discovery that on average nearly half of foods distributed by food shelves were not obtained from food banks have implications for our approach to calculating the HEI and are described later in the paper.

\section{Statistical analysis}

Food shelves' characteristics were summarized and presented using means and ranges for continuous variables, frequencies and percentages for categorical variables. HEI-2010 total and component scores were calculated and presented using means and standard deviations. Note that 'less healthy' items like sodium and empty calories are reverse scored so that a high score is a 
better score. Linear mixed models were used to evaluate seasonal differences in HEI-2010 total score. Analysis was performed in 2015 using the statistical software package SAS version 9.3. A two-sided $P$ value $<0.05$ was considered statistically significant.

\section{Results}

Table 2 identifies the nutritional quality of the foods ordered by food shelves from food banks in Minnesota and Wisconsin, USA as evaluated by the mean HEI-2010 total and component scores. The mean total HEI-2010 score for the 269 food shelves was 62.7 out of 100 with a range of 28-82. Mean component scores for total protein foods, total vegetables, fatty acids, and seafood and plant proteins were the highest. The mean whole grains component score was the lowest followed by diary, total fruits, whole fruits, sodium and refined grains.

Table 3 identifies the average HEI-2010 total scores for 2013 by geographic location and size. Scores identify better overall HEI-2010 scores for micropolitan and large food shelves. Small food shelves and those in small towns have the lowest mean and maximum total HEI scores.

Figure 2 provides the mean total HEI-2010 scores by month and quarter and suggests a seasonal difference in scores. The May mean HEI-2010 score is significantly higher than December's score (60v. 52, $P=0 \cdot 0001$ ); the June mean HEI-2010 score is significantly higher than October $\quad(P=0.0001)$, November $(P=0.0117)$ and December $(P=<0 \cdot 0001)$; and the July $(P=0 \cdot 0001)$, August $(P<0.0001)$ and September $(P=0.0004)$ scores are significantly higher than the December score. A quarterly evaluation reveals that mean HEI scores are higher in the summer months. Quarter 1 is significantly lower than quarter $2(59 \cdot 5 v .62 \cdot 7, P=0.0035)$ and quarter $3(59.5 v$. 63.1, $\quad P=0.0007)$. Quarter 3 is significantly higher than quarter $4(63 \cdot 1 v \cdot 60 \cdot 1, P=0 \cdot 0221)$. In general, the aggregated quarterly scores are higher than the monthly scores. Average quarterly component scores provide some additional insight. There is a spike in average whole grain scores in quarter 3 (quarter $2=2.5 v$. quarter $3=3 \cdot 7$, $P<0.0001$ ) and dairy scores in quarters 3 and 4 (quarter $2=3.9 v$. quarter $3=5.2$ and quarter $4=5.4, P<0.0001$ ). Average fatty acid ratio (7.9) and empty calorie (13.8) scores are lowest in quarter 1 . The average refined grains score is lowest in quarter 4 (4.6). Details of the monthly and quarterly component scores are available from the authors upon request.

\section{Strengths and limitations}

Application of the HEI-2010, an objective, science-supported tool in alignment with the Dietary Guidelines for Americans, in the food shelf setting is a strength of the present study. Additionally, the use of electronic invoices has the potential to greatly reduce the cost of manually collecting inventory data on food and quantities and is a major innovation of the Healthy FOOD study. Our evaluation approach to characterize the healthfulness of the hunger relief food supply using the HEI-2010 has limitations to be considered while cautiously interpreting the study findings. First, the potential for coding errors needs to be considered. The FNDDS 5.0 is limited to about 7200 unique foods. This was particularly problematic when coding culturally specific foods such as sauces. The FNDDS 5.0 also lacks several specific products like 'vanilla' Sunflower beverage. FNDDS 5.0 codes describe predominantly prepared instead of unprepared foods. This was also challenging as many food shelf items are unprepared. For example, the product invoice listed the product as white cake mix and the only FNDDS 5.0 code similar enough was 'cake, white, prepared, no frosting'. It is unclear the extent that use of the FNDDS 5.0 'as prepared' codes as a substitute for the many food shelf items that are unprepared foods affected the HEI total and component score values. Second, the use of invoices to measure healthfulness of food shelves also has the potential for coding errors. Invoices sometimes lacked product specificity. For example, unspecified 'corn' could potentially

Table 2 Heathy Eating Index-2010 (HEl-2010) total and component scores for 269 Minnesota and Wisconsin (USA) food shelves, 2013

\begin{tabular}{|c|c|c|c|c|c|}
\hline Component & HEI-2010 score mean & SD & Range & Maximum possible & Qualifications for maximum \\
\hline Total Fruits & 2.4 & 1.2 & $0-5$ & 5 & $\geq 0.8$ cup-equivalents $/ 1000 \mathrm{kcal}$ \\
\hline Whole Fruits & $2 \cdot 7$ & 1.4 & $0-5$ & 5 & $\geq 0.4$ cup-equivalents $/ 1000 \mathrm{kcal}$ \\
\hline Total Vegetables & $4 \cdot 2$ & $1 \cdot 2$ & $0-5$ & 5 & $\geq 1 \cdot 1$ cup-equivalents $/ 1000 \mathrm{kcal}$ \\
\hline Greens and Beans & $2 \cdot 8$ & $2 \cdot 0$ & $0-5$ & 5 & $\geq 0.2$ cup-equivalents $/ 1000 \mathrm{kcal}$ \\
\hline Whole Grains & $2 \cdot 9$ & $2 \cdot 1$ & $0-10$ & 10 & $\geq 1.5$ cup-equivalents $/ 1000 \mathrm{kcal}$ \\
\hline Dairy & 4.7 & $2 \cdot 7$ & $0-10$ & 10 & $\geq 1.3$ cup-equivalents $/ 1000 \mathrm{kcal}$ \\
\hline Total Protein Foods & $4 \cdot 4$ & 1.3 & $0-5$ & 5 & $\geq 2.5$ ounce-equivalents $/ 1000 \mathrm{kcal}$ \\
\hline Seafood and Plant Proteins & $4 \cdot 0$ & 1.6 & $0-5$ & 5 & $\geq 0.8$ ounce-equivalents $/ 1000 \mathrm{kcal}$ \\
\hline Fatty Acids & 8.4 & 2.6 & $0-10$ & 10 & $(\mathrm{PUFA}+\mathrm{MUFA}) / \mathrm{SFA} \geq 2.5$ \\
\hline Refined Grains & $5 \cdot 3$ & 3.4 & $0-10$ & 10 & $\leq 1.8$ ounce-equivalents $/ 1000 \mathrm{kcal}$ \\
\hline Sodium & $5 \cdot 3$ & 2.9 & $0-10$ & 10 & $\leq 1.1 \mathrm{~g} / 1000 \mathrm{kcal}$ \\
\hline Empty Calories & $15 \cdot 4$ & 3.9 & $0-20$ & 20 & $\leq 19 \%$ of energy \\
\hline Total & $62 \cdot 7$ & 9.4 & $28-82$ & 100 & Obtain maximum score in all components \\
\hline
\end{tabular}

$1000 \mathrm{kcal}=4184 \mathrm{~kJ}$. 
Table 3 Heathy Eating Index-2010 (HEl-2010) scores by food shelf location and size characteristics, Minnesota and Wisconsin (USA), 2013

\begin{tabular}{lrcr}
\hline Food shelf & $n$ & HEI-2010 score mean & Range \\
\hline Location* & & & \\
$\quad$ Metropolitan & 186 & 63.05 & $28-82$ \\
$\quad$ Micropolitan & 13 & 66.92 & $52-78$ \\
$\quad$ Small town & 23 & $60 \cdot 13$ & $44-68$ \\
$\quad$ Rural & 47 & 61.40 & $40-80$ \\
Size† & & & \\
$\quad$ Small (475-35450 lb) & 67 & 56.43 & $28-78$ \\
Small-medium (35680-99 165 lb) & 67 & 62.57 & $40-80$ \\
$\quad$ Medium-large (102245-269413 lb) & 68 & 63.76 & $46-80$ \\
Large (272247-2302500 lb) & 67 & 68.03 & $50-82$ \\
\hline
\end{tabular}

$1 \mathrm{lb}=0.454 \mathrm{~kg}$.

*Location is defined by assigning Rural-Urban Commuting Area Codes ${ }^{(26)}$ to each food shelf address.

†Size categories are determined by calculating quartiles from pounds (lb) of food distributed in 2013 from 269 food shelves. Pounds distributed represents reported data from food shelves to food bank(s).

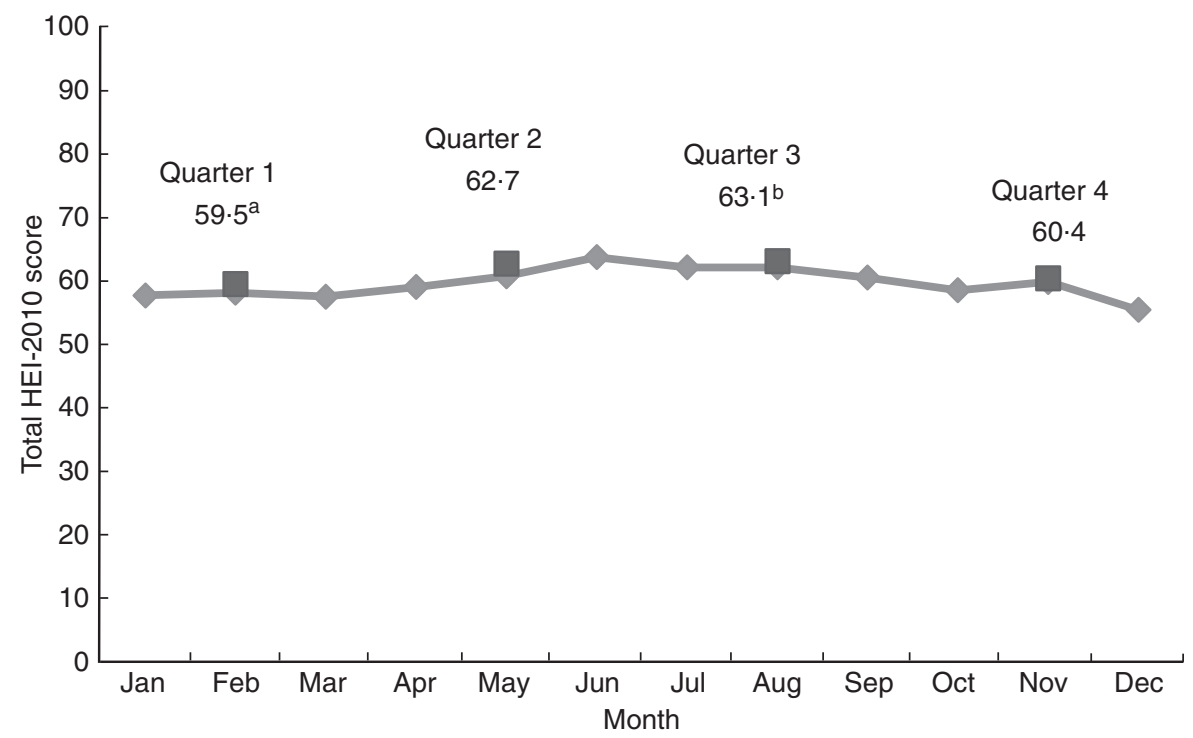

Fig. 2 Heathy Eating Index-2010 (HEl-2010) total score for 269 Minnesota and Wisconsin (USA) food shelves by month ( $-\backsim)$ and quarter $(\square)$, 2013. a Quarter 1 (Jan, Feb, Mar) is significantly lower than quarter 2 (Apr, May, Jun; 59.5 V. 62.7, $P=0.0035$ ) and quarter 3 (Jul, Aug, Sep; 59.5 v. 63.1, $P=0.0007$ ). ${ }^{b}$ Quarter 3 (Jul, Aug, Sep) is significantly higher than quarter $4(O c t$, Nov, Dec; 63.1 v. $60 \cdot 1, P=0.0221)$

be assigned a variety of codes (e.g. canned/frozen, no/low sodium). More problematic, some invoices contained any of the following miscellaneous product categories: meat/ poultry, dairy, dry goods, produce, seafood, beverages, bakery, deli and frozen. These nine categories were determined by the food banks. Our study revealed that $27 \%$ of all foods ordered by food shelves were described as 'miscellaneous' on invoices. This food often arrives at food banks highly perishable (e.g. produce), unsorted or mislabelled due to limited donor time or resources (e.g. food drives) and is quickly dispersed without the details of the products being recorded. Similarly, mixed boxes of dry foods often contain anything from cereal to pre-packaged cheese and crackers. In other cases, miscellaneous food was labelled 'deli' because it was located in the deli section of the grocery store. Miscellaneous foods lacked the specificity to be assigned an FNDDS 5.0 code, therefore were not linked to the FPED 2009-10 and not included in the HEI-2010 scores.

Also, our evaluation approach represents foods ordered by each food shelf from food banks. This does not capture all foods distributed by a food shelf. From our study, we estimated that $48 \%$ of food distributed was not ordered from food banks and, therefore, not reflected in the invoices. Donations made directly to food shelves, foods purchased directly by the food shelf from sources other than food banks, and other food procurement opportunities were not included in our calculations of the HEI-2010. It is unclear whether a more comprehensive measure capturing all foods obtained and/or distributed would reveal lower, higher or about the same HEI-2010 total and component scores as compared with our study 
findings. Finally, our study evaluated one aspect of the hunger relief system and did not include hot meal programmes or other meal delivery systems.

\section{Discussion}

Application of the HEI-2010 to the local hunger relief setting is feasible and has the potential to address gaps in the research literature and practice. Our approach revealed an average score of 63 out of 100 . This represents a score of 'needing improvement'. In context, a score of over 80 represents 'good' and a score of less than 51 is 'poor' ${ }^{\text {(14) }}$. The majority ( $89 \%$ ) of food shelf scores fell within the 'needs improvement' category. Only $2 \%$ of food shelves achieved a score of 'good' and 9\% had scores in the 'needs substantial improvement' category. This may be a result of concerted efforts to improve the emergency food supply ${ }^{(27)}$. Previous applications to other food environments provided a snapshot of a fast-food dollar menu score of 43.4, the 2010 US food supply score of 55 (improved from 48 in 1970) and the twenty child-care menus in North Carolina, USA (2005-2006) that received a score of 59.1, revealing on average lower scores than our study food shelves ${ }^{(15,19-21)}$. Our findings identified that mean component scores for total protein foods, total vegetables, fatty acids, and seafood and plant proteins were the highest. This is consistent with foods distributed through the USDA's Emergency Food Assistance Program (TEFAP) which in 2009 provided 729.6 million $\mathrm{lb}$ (331.2 million $\mathrm{kg}$ ) of food to food banks to distribute to soup kitchens and food pantries ${ }^{(28)}$. Based upon total weight, $64 \%$ of all foods delivered were vegetables, meat, starches and peanut butter/dried beans ${ }^{(28)}$. Similarly, a study evaluating the inventory from one food bank in Mesa, Arizona, USA to determine whether foods procured complied with the MyPlate recommendations for clients showed that the inventory could meet the minimum requirements for protein and grains for a package serving a family of four for $3 \mathrm{~d}^{(29)}$. Our findings identified that the mean whole grains component score was the lowest followed by diary, total fruits, whole fruits, sodium and refined grains. In 2009, TEFAP distributed fewer of these items: $17 \%$ juice, $11 \%$ fruit, $5 \%$ milk, $2 \%$ cereal and $<1 \%$ grains ${ }^{(28)}$. This is also consistent with the Arizona food bank evaluation where the inventory did not meet minimum vegetable, fruit or dairy requirements based upon a package for a family of four ${ }^{(29)}$.

The Healthy FOOD study results describe HEI-2010 score variations by geographic location, size and season. Small food shelves, defined in the present study based on pounds distributed, may rely more on donated foods and have limited storage space, resulting in a lower HEI score. A 2011 survey administered to thirty-eight Minnesota food shelves identified that larger food shelves were more likely to have healthy food sourcing and distributing policies and purchase more food than received as donations ${ }^{(30)}$.
In our study, small town and rural located food shelves appear to have lower HEI-2010 scores. A Feeding America 2014 report identifies families living in rural communities with higher food insecurity than the national average ${ }^{(3)}$. Evaluations of access to healthy food in other settings also identify less healthful offerings in rural communities. An evaluation of 6732 middle-, junior- and senior high-schools across twenty-eight US states identified significantly more junk food available in rural schools compared with urban schools ${ }^{(31)}$. A survey among a random sample of about 823 licensed child-care providers in Minnesota and Wisconsin, USA revealed that limited access to healthy foods in rural areas was a barrier to providing healthy foods to pre-school children ${ }^{(32)}$. Also consistent with our findings, Rural Healthy People 2020 recognizes the need to focus on healthy eating in rural communities and identifies nutrition among its top five priorities $^{(33)}$. Addressing inequitable access to healthy food is an urgent global issue ${ }^{(34,35)}$. Finally, seasonal differences in the HEI-2010 scores were observed. Not surprisingly, summer months, which are peak growing months in Minnesota and Wisconsin, had higher scores than winter months. Eating more seasonal food is one proposal for moving towards more sustainable consumption patterns as a global strategy to reduce the environmental impact of the diet ${ }^{(36)}$.

Our approach revealed that the food supplied by food banks represents only about half of the food hunger relief agencies distribute. The proportion of food obtained from food banks varied widely across food shelves, ranging from a high of $99 \%$ to as little as 3\%. Furthermore, the set of food items in a food bank's inventory changed frequently, and each new item needed to be assigned a food code and mapped to the FNDDS 5.0 and FPED 2009-10 databases. In addition, 27\% of foods that food banks made available were 'miscellaneous' foods that were not mapped to the USDA food codes. Therefore, a more comprehensive, less labour- and data-intensive measure for characterizing the healthfulness of food distributed by hunger relief agencies needs to be developed. In one study, personnel from twenty food banks voiced concern with tools that require extensive nutrition expertise and recommended a system that all food banks can use to evaluate their inventories was needed $^{(27)}$. Responding to these limitations, a modified approach is currently under development by the study team and described elsewhere ${ }^{(37)}$. The Hunger Relief Nutrition Index (HRNI) has the potential to be administered at the local agency level at the point of purchase and correlates well with the HEI-2010 ${ }^{(37)}$.

\section{Conclusion and implications}

Healthy food environments are necessary to ensure that healthy choices can be made by individuals ${ }^{(38)}$. 
This is especially important for those experiencing the extra burden of diet-related diseases and complications as low-income food shelf clients do ${ }^{(39)}$. To the best of our knowledge, approaches to systematically measure the healthfulness of the foods available in a local hunger relief agency (e.g. food shelf) are non-existent. Previous attempts have been focused mostly on the availability of healthy foods ${ }^{(40,41)}$. There is evidence of interest among stakeholders for a standardized and comprehensive system to measure the healthfulness of food in the hunger relief system $^{(27)}$.

Comprehensive food policy approaches are required to make a population impact on hunger and require substantial political and organizational commitment ${ }^{(34,42)}$. Strategies targeted to improve healthy food access for low-income people can result in benefits for the broader community ${ }^{(43)}$. The impact of providing HEI scores to local decision makers in the hunger relief setting is an issue for urgent study. HEI interventions could target local decision makers including food bank or food shelf staff responsible for food ordering. For example, providing periodic HEI total and component scores to directors and managers could be used to establish programme goals, donor education, and to aid future ordering decisions and priorities. The approach and lessons learned from the Healthy FOOD study provide an important foundation to build upon.

\section{Acknowledgements}

Financial support: Funding for this project was provided by the University of Minnesota Healthy Foods, Healthy Lives Institute. The Healthy Food Healthy Lives Institute had no role in the design, analysis or writing of this article. Conflict of interest: None. Authorship: M.S.N. led the formulation of research questions, designing the study, carrying it out and writing the article. K.Y.G. provided nutrition expertise for food coding and writing the article. C.C. provided data management and contributed to writing the article. C.H. provided overall project management to carry out the study, including food coding, and contributed to the writing. M.J. performed all programming tasks, processed the data and contributed to the writing. Q.W. contributed to the data analysis and to writing the article. C.W. contributed to carrying out the study, conducted the data analysis and contributed to writing the article. R.P.K. co-led the formulation of research questions, designing the study, carrying it out and writing the article. R.P.K. oversaw the data analysis. Ethics of human subject participation: Not applicable.

\section{References}

1. Feeding America (2014) 2014 Annual Report: Bringing Hope to 46 Million People. http://www.feedingamerica.org/ourresponse/about-us/annual-report/2014-annual-report.pdf (accessed June 2015).
2. Campbell E, Webb K, Ross M et al. (2015) NutritionFocused Food Banking. Discussion Paper. Washington, DC: Institute of Medicine; available at http://nam.edu/ perspectives-2015-nutrition-focused-food-banking/

3. Weinfield N, Mills G, Borger C et al. (2014) Hunger in America 2014. National Report Prepared for Feeding America. http://help.feedingamerica.org/HungerInAmerica/ hunger-in-america-2014-full-report.pdf (accessed June 2015).

4. Coleman-Jensen A, Rabbit M, Gregory C et al. (2015) Household Food Security in the United States in 2014, Economic Research Report no. ERR-194. Washington, DC: US Department of Agriculture, Economic Research Service.

5. Drewnowski A \& Specter S (2004) Poverty and obesity: the role of energy density and energy costs. Am J Clin Nutr $\mathbf{7 9}$, 6-16.

6. Leung C, Epel E, Ritchie L et al. (2014) Food insecurity is inversely associated with diet quality of lower-income adults. J Acad Nutr Diet 114, 1943-1953.

7. Becquey E, Delpeuch F, Konate A et al. (2012) Seasonality of the dietary dimension of household food security in urban Burkina Faso. Br J Nutr 107, 1860-1870.

8. Hirvonen K, Taffesse A \& Worku Hassen I (2015) Seasonality and household diets in Ethiopia. Public Health Nutr (Epublication ahead of print version).

9. Hillbruner C \& Egan R (2008) Seasonality, household food security, and nutritional status in Dinajpur, Bangladesh. Food Nutr Bull 29, 221-231.

10. US Department of Agriculture, Food and Nutrition Service (2014) Programs and Services. http://www.fns.usda.gov/ programs-and-services (accessed June 2015).

11. US Department of Agriculture, Food and Nutrition Service (2016) Women, Infants, and Children (WIC). http:// www.fns.usda.gov/wic/women-infants-and-children-wic (accessed May 2016).

12. US Department of Agriculture, Food and Nutrition Service (2015) Child and Adult Care Food Program (CACFP). http:// www.fns.usda.gov/cacfp/child-and-adult-care-food-program (accessed May 2016).

13. US Department of Agriculture, Food and Nutrition Service (2016) National School Lunch Program (NSLP). http://www. fns.usda.gov/nslp/national-school-lunch-program-nslp (accessed May 2016).

14. Guenther P, Reedy J, Krebs-Smith S et al. (2007) Development and Evaluation of the Healthy Eating Index-2005: Technical Report. Alexandria, VA: US Department of Agriculture, Center for the Nutrition Policy and Promotion.

15. Reedy J, Krebs-Smith S \& Bosire C (2010) Evaluating the food environment. Application of the Healthy Eating Index2005. Am J Prev Med 38, 465-471.

16. Ford E, Zhao G, Tsai J et al. (2011) Low-risk lifestyle behaviors and all-cause mortality: findings from the National Health and Nutrition Examination Survey III Mortality Study. Am J Public Health 101, 1922-1929.

17. Guo X, Warden B, Paeratakul S et al. (2004) Healthy eating index and obesity. Eur J Clin Nutr 58, 1580-1586.

18. Chiuve S, Fung T, Rimm E et al. (2012) Alternative dietary indices both strongly predict risk of chronic disease. J Nutr 142, 1009-1018.

19. Erinosho T, Ball S, Hanson P et al. (2013) Assessing foods offered to children at child-care centers using the Healthy Eating Index-2005. J Acad Nutr Diet 113, 1084-1089.

20. Miller P, Reedy J, Kirkpatrick S et al. (2014) The United States food supply is not consistent with dietary guidance: evidence from an evaluation using the Healthy Eating Index-2010. J Acad Nutr Diet 115, 95-100.

21. Krebs-Smith S, Reedy J \& Bosire C (2010) Healthfulness of the U.S. food supply: little improvement despite decades of dietary guidance. Am J Prev Med 38, 472-477. 
22. US Department of Agriculture, Agricultural Research Service (2012) Food and Nutrient Database for Dietary Studies, 5.0. Food Surveys Research Group Home Page. http://www.ars. usda.gov/ba/bhnrc/fsrg (accessed February 2014).

23. US Department of Agriculture, Agricultural Research Service (2015) National Nutrient Database for Standard Reference. http://ndb.nal.usda.gov/ (accessed February 2015).

24. Bowman S, Clemens J, Thoerig R et al. (2013) Food Patterns Equivalents Database 2009-10: Methodology and User Guide. Beltsville, MD: US Department of Agriculture, Agricultural Research Service.

25. National Cancer Institute (2015) HEI Tools For Researchers. http://epi.grants.cancer.gov/hei/tools.html (accessed February 2015).

26. US Department of Agriculture, Economic Research Service (2014) Rural-Urban Commuting Area Codes. http://www. ers.usda.gov/data-products/rural-urban-commuting-area-codes. aspx (accessed February 2015).

27. Handforth B, Hennink M \& Schwartz M (2013) A qualitative study of nutrition-based initiatives at selected food banks in the Feeding America Network. J Acad Nutr Diet 113, 411-415.

28. Zimmerman T, Dixit-Joshi S, Sun B et al. (2012) Nutrient and MyPyramid Analysis of USDA Foods in Five of Its Food and Nutrition Programs. Report FD-12-USDAFOODS. Alexandria, VA: US Department of Agriculture, Food and Nutrition Service, Office of Research and Analysis.

29. Lick L (2014) Applying MyPlate to procurement in food banks: implications for policy. MS Thesis, Arizona State University; available at http://gradworks.umi.com/15/94/ 1594257.html

30. Rochester JS, Nanney MS \& Story M (2011) Assessing foodshelves' ability to distribute healthy foods to foodshelf clients. J Hunger Environ Nutr 6, 10-26.

31. Nanney MS, Davey CS \& Kubik MY (2013) Rural disparities in the distribution of policies that support healthy eating in US secondary schools. J Acad Nutr Diet 113, 1062-1068.

32. Nanney MS (2014) Healthy Eating and Physical Activity Practices in Rural Child Care Settings. Bozeman, MT: International Rural Health and Rural Nursing Conference.
33. Bolin J \& Bellamy G (2014) Rural Healthy People 2020 Public Health Texas A\&M Health Sciences Center. http:// sph.tamhsc.edu/srhrc/rhp2020.html (accessed February 2015).

34. Caritas Europa (2014) Food Security Report 2014: The EU's Role to End Hunger by 2025. http://www.caritas.eu/sites/ default/files/caritas_europa_food_security_report_2014_-_eu _role_to_end_hunger.pdf (accessed October 2015).

35. Food and Agriculture Organization of the United Nations, International Fund for Agricultural Development \& World Food Programme (2014) The State of Food Insecurity in the World 2014. Strengthening the Enabling Environment for Food Security and Nutrition. Rome: FAO; available at http://www.fao.org/3/a-i4030e.pdf

36. Macdiarmid JI (2014) Seasonality and dietary requirements: will eating seasonal food contribute to health and environmental sustainability? Proc Nutr Soc 73, 368-375.

37. King RP, Warren C, Cureton C et al. (2016) How healthy is hunger relief food? Am J Agric Econ 98, 533-548.

38. Story M, Kaphingst K, Robinsin-O'Brien R et al. (2008) Creating healthy food and eating environments: policy and environmental approaches. Annu Rev Public Health 29, 253-272.

39. Meyer P, Yoon P \& Kaufman R (2013) CDC Health Disparities and Inequalities Report - United States 2013. MMWR 62, Suppl., S1-S187.

40. Hoisington A, Manore MM \& Raab C (2011) Nutritional quality of emergency foods. J Acad Nutr Diet 111, 573-576.

41. Seidel M, Laquatra I, Woods M et al. (2015) Applying a nutrient-rich foods index algorithm to address nutrient content of food bank food. J Acad Nutr Diet 115, 695-700.

42. Robert Wood Johnson Foundation (2014) Healthy Policy Snapshot: Childhood Obesity. Declining childhood obesity rates - where are we seeing signs of progress? http://www. rwjf.org/content/dam/farm/reports/issue_briefs/2015/rwjf 401163 (accessed June 2015).

43. Bell J, Mora G, Hagan E et al. (2013) Access to Healthy Food and Why it Matters: A Review of the Research. Policy Link and The Food Trust. https://www.policylink.org/ sites/default/files/GROCERYGAP_FINAL_NOV2013.pdf (accessed June 2015). 